\title{
A influência do sentido da vida sobre o bem estar
}

\section{The influence of meaning of life on well-being}

DOI: $10.46919 / \operatorname{archv1n6-006}$

Recebimento dos originais: 01/09/2020

Aceitação para publicação: 30/10/2020

\section{Lucia Helena Walendy de Freitas}

Mestre em Psicologia da Saúde pela Universidade Metodista de São Paulo;

Trabalha , em consultório próprio, na cidade de São Paulo, com desenvolvimento humano por meio de

Psicologia Positiva, Terapia do Sentido, Terapia Sistêmica e Yogaterapia Integral.

E-mail: florescer.suporte@gmail.com

\section{RESUMO}

Este estudo teve por objetivo analisar as relações de influência entre o sentido atribuído à vida, o suporte social e o bem estar, bem como verificar a influência da idade sobre essas fatores. Participaram da pesquisa 205 trabalhadores entre 16 e 88 anos, 65,4\% sexo feminino. Os instrumentos de coleta de dados foram: Dimensão Existencial da Escala de Bem Estar Espiritual; Escalas de Bem Estar Psicológico; Bem Estar Subjetivo e de Percepção de Suporte Social e dados demográficos. As análises revelaram que com o avançar da idade, há uma tendência a aumentarem os níveis de significados positivos atribuídos à vida; o apoio social é maximizado quando favorece a emergência do Sentido; bem como confirma a Logoterapia quando afirma que o Sentido é a causa essencial do bem estar e felicidade.

Palavras-chave: bem estar psicológico, bem estar subjetivo, apoio social, sentido da vida.

\begin{abstract}
This study aimed to analyze the relations of influence between the meaning attributed to life, social support and well-being as well as to evaluate the influence of age on these factors. 205 employees participated in the survey between 16 and 88 years, 65.4\% female. The instruments for data collection were: existential dimensions of Spiritual Wellness Scale; Scales of psychological well-being; Subjective well-being and Perceived Social Support and demographics. The analysis revealed that, with increasing age, there is a trend of increasing levels of positive meaning to life; Social support is maximized when it favors the emergence of meaning in life; and confirm the Logotherapy which affirm that the meaning is a main causal factor of well-being and happiness.
\end{abstract}

Keywords: psychological well-being, subjective well-being, social support, meaning of life.

\section{INTRODUÇÃO}

Segundo a conceituação da Logoterapia, o ser humano é composto pela dimensão biológica, psicológica, social e espiritual. Nesse contexto, a dimensão biológica corresponde ao corpo físico; a dimensão psicológica é composta por processos mentais relacionados com o desejo de prazer, de poder, com a aprendizagem e o condicionamento; a dimensão social está relacionada à cultura, às instituições e aos relacionamentos; e a dimensão espiritual refere-se à capacidade de fazer escolhas (livre arbítrio e 
responsabilidade), de atribuir valor às coisas, de dar sentido à vida e às respectivas situações. Essa dimensão espiritual corresponde à dimensão de significados essenciais que surgem por meio da motivação humana inerente e primária para encontrar o sentido de sua existência - a Vontade de Sentido (Frankl, 2003; 2013; Rodrigues, 1991).

De acordo com Frankl $(2003 ; 2013)$ o desejo de significado está subjacente aos demais desejos, de modo que estrutura todas as motivações e situações em todos os momentos da vida humana. Dessa motivação primordial para encontrar sentido, surge uma rede básica de significados essenciais, uma visão de mundo que afirma a vida incondicionalmente e proporciona um sentido estruturante, que faz com que as pessoas, no dia a dia, encontrem orientação e forças para enfrentar a sua existência. Isto quer dizer que a motivação humana essencial pela busca do sentido estrutura e orienta todas aspirações, metas, reações emocionais, identidade e autoestima, satisfação, atitudes, comportamentos, etc. Nessa perspectiva portanto, todo estado de saúde ou de doença depende, em algum nível, do quanto o ser humano entra em contato com seu mundo espiritual de valores e de significados.

Considerando-se esses pressupostos, é possível supor que tanto os níveis de felicidade quanto os de saúde estejam relacionados aos níveis de sentido atribuído à vida.

Em psicologia, a felicidade é objeto de pesquisas sobre Bem Estar. Esse campo de pesquisa diz respeito aos processos objetivos e subjetivos que levam as pessoas a avaliarem o grau de felicidade em suas vidas. Os estudos sobre Bem Estar estão fundamentados em duas grandes perspectivas: a visão eudaimônica e a e a visão hedônica.

A eudaimônica consiste da visão de que o bem estar e a felicidade estão relacionadas ao desenvolvimento de virtudes e ao autoaperfeiçoamento. A corrente hedônica está associada à visão de que o bem estar e a felicidade dependem de fatores que favoreçam o equilíbrio emocional e a satisfação com a vida. Entre os estudos desenvolvidos sob a ótica da visão eudaimônica destaca-se a pesquisa desenvolvida por Carol Ryff e colaboradores sobre o conceito de Bem Estar Psicológico e sob a ótica da hedônica destaca-se a pesquisa desenvolvida por Ed Diener e colaboradores sobre o conceito denominado de Bem Estar Subjetivo ou Bem Estar Emocional. Além dessas duas perspectivas de bem estar, destacase a pesquisa de Christopher Ellison sobre o conceito de Bem Estar Espiritual, que tem por objetivo focar os aspectos transcendentais relativos ao bem estar religioso e existencial (Keyes, C. L. M., Shmotkin, D. \& Ryff, C. D., 2002; Ellison, C. G.; Levin, J. S., 1998).

Essas três visões do bem estar - Psicológico, Subjetivo/Emocional e Espiritual compõem um corpo de estudo, que em parte, está associado a duas das quatro dimensões humanas definidas pela Logoterapia - as dimensões psicológica e a espiritual. 
Outro aspecto importante a ser considerado nos níveis de saúde e de bem estar consiste da dimensão social que pode ser representada, em parte, pelo estudo dos níveis de Suporte Social, isto é, os níveis de suporte disponível na rede social de apoio durante todo o ciclo da vida. De acordo com Cobb (1976) o Suporte Social deve estar presente em todo o ciclo de desenvolvimento da vida, porque deve se iniciar no ventre materno com apoio à maternidade, ao nascimento e à nova vida que se inicia, bem como continuar presente ao longo de todas fases de estresse e transições do ciclo de vida.

Em face dessas considerações é possível supor que, ao longo da vida, existam relações entre os níveis de significados transcendentes atribuídos à vida e os níveis de bem estar. Além disso, pode-se supor que, nas relações entre os níveis de sentido transcendente e os de bem estar, seja o apoio social um mediador preventivo do estresse, capaz de favorecer a manutenção dos níveis felicidade e também possa ser considerado como um pilar que sustenta as pessoas a continuarem expressando seus significados transcendentais, mesmo em situações de estresse.

Nesse contexto, o objetivo deste estudo consistiu em verificar como essas relações acontecem, bem como refletir brevemente sobre as consequências que elas têm sobre as intervenções de Suporte Social nos contextos organizacional e clínico.

\section{FUNDAMENTAÇÃO TEÓRICA}

A Vontade de Sentido é definida como sendo de natureza inata e primária e, portanto, préexistente a todo aprendizado, memória ou consciência e, por isso, não está sujeita aos movimentos biológicos ou mecânicos materiais. Da falta de contato com o sentido surge o vazio existencial ou frustração existencial, da qual decorre a neurose noogênica de origem espiritual que se caracteriza pela sede de significado e de valor e se apresenta como um substitutivo do sentido. (Frankl, 2003a; Rodrigues, $\mathrm{R}, 1991)$.

Nessa acepção, a capacidade de alguém existir ou viver feliz e saudavelmente, ao invés de apenas subexistir ou sobreviver aos desequilíbrios e doenças, estaria associada à capacidade de autotranscendência. A autotranscendência diz respeito ao sentido que uma pessoa encontra em consagrarse, na vida cotidiana, a algo maior do que ela mesma, como a dedicação à realização de algo para outro ser humano ou à uma causa ou a dedicação à uma pessoa amada. A vivência da autotranscendência tem como consequência um senso de identidade, de autorrealização e de felicidade.

Frankl (2013) afirma que os desejos de poder e de prazer ou vontade de poder e vontade de prazer são manifestações secundárias ou derivações da vontade primordial de sentido. Em sua cosmovisão, a Vontade de Sentido é definida como sendo "o esforço mais básico do homem na direção de encontrar e realizar sentidos e propósitos". Nesse contexto, o poder é um meio para encontrar a finalidade que é o 
próprio sentido; e o prazer é um efeito do sentido encontrado. Além disso, esse autor afirma que da vontade de sentido emanam a motivação ou "uma razão para ser feliz" e a própria busca pela felicidade.

Estudo de Oliveira e Silva (2013) com 146 idosos mostrou que há uma associação fortemente significativa e positiva $(r=055)$ entre bem estar psíquico e a presença do sentido entre os idosos pesquisados. Além disso, os autores destacaram que o idoso pode encontrar sentido para sua vida, sobretudo se ele tiver a percepção de que está socialmente apoiado, contudo esses recursos sociais não são plenamente responsáveis pelos índices positivos encontrados, mas sim a qualidade das relações que podem favorecer a emergência do sentido. Este estudo sugere que os significados que dão sentido à vida são capazes de influenciar e portanto em parte proporcionar os bons níveis de bem estar psíquico constatados.

Estudo de Simões, Kluppel e Sousa (2012) com 92 psicólogos de hospitais públicos com idade entre 24 a 60 anos mostrou, entre outros, que o Bem Estar Existencial está significativamente e negativamente correlacionado com os indicadores de exaustão emocional $(r=-0,43)$ e positivamente relacionado com os indicadores de realização profissional $(r=0,42)$, mostrando com isso que há uma tendência de que quando há bons índices de Bem Estar Existencial ocorra baixos níveis de exaustão e aumento dos sentimentos relativos à realização profissional. Este estudo sugere que os significados existenciais sejam um fator de influência que cause, pelo menos em parte, os menores índices de exaustão e portanto de maior bem estar e de maiores níveis de autorrealização.

Estudo de Walendy de Freitas (2014) com 205 trabalhadores na ativa e aposentados entre 16 a 88 anos mostrou que há relações de influência significativas e diretas entre o Bem Estar Espiritual, o Psicológico e o Subjetivo. Esse estudo mostrou que, além dessas influências diretas, o suporte social também contribui como um mediador entre essas relações. Além disso, o estudo mostrou que os níveis de percepção de suporte social e das três dimensões de bem estar: espiritual, psicológico e subjetivo são significativamente maiores quando o indivíduo tem uma percepção de que sua saúde é boa.

Em face das constatações dessas pesquisas, que analisaram a felicidade em termos de conceitos psicológicos de bem estar, bem como do modelo proposto pela Logoterapia em que a felicidade é o produto do sentido, é possível supor que o sentido atribuído à vida seja um antecedente causal do bem estar.

\section{CONCEITOS SOBRE BEM ESTAR}

Há dois conceitos que fundamentam os estudos psicológicos sobre a felicidade: o conceito de Bem Estar Psicológico e o de Bem Estar Subjetivo. O conceito de Bem Estar Psicológico surgiu com base em teorias humanistas que envolvem formulações sobre o desenvolvimento humano e atitudes ante os 
desafios existenciais da vida. O conceito de Bem Estar Subjetivo é definido em termos de reações emocionais e de satisfação com a vida. Além dessas duas formulações, há o conceito de Bem Estar Espiritual relacionado aos significados transcendentais associados à religiosidade e aos sentidos existenciais atribuídos á vida.

O Bem Estar Psicológico é um conceito que expressa a percepção que as pessoas têm do próprio envolvimento com desafios existenciais da vida e, sendo assim, tem por finalidade expressar o grau de funcionamento psicológico. Esse conceito é definido por seis dimensões que refletem seis maneiras diferentes de agir, de forma positiva, quando em confronto com os desafios da vida. Essas seis dimensões são: autonomia, domínio do ambiente, crescimento pessoal, relações positivas com os outros, o propósito na vida, e autoaceitação. A autonomia é definida em termos de níveis de pensamento de autodeterminação e independência; capacidade de resistir à pressão social; e capacidade de regular o próprio comportamento a partir do interior, da própria subjetividade. Domínio ambiental é definido em termos de níveis de um senso de domínio e competência na gestão do meio em que alguém atua; no controle do complexo conjunto de atividades externas ao fazer uso efetivo de oportunidades que existem ao redor; e de níveis da capacidade de escolher ou criar contextos adequados às necessidades externas em consonância com os valores pessoais. O crescimento pessoal é definido em termos de níveis de sentimentos de estar em contínuo desenvolvimento, crescimento e expansão; de ter abertura a novas experiências; e de capacidade de realizar o próprio potencial. Relações positivas com os outros é definido em termos de níveis de satisfação e confiabilidade nos relacionamentos; de níveis de preocupação com o bem estar dos outros; e de níveis de empatia, afeto e intimidade para com os outros. Propósito na vida é definido em termos de níveis de crenças sobre a finalidade da vida; objetivos na vida; e um senso de direção, bem como de sentimentos sobre o sentido da vida presente e passada. A autoaceitação é definida em termos de níveis de atitudes positivas em relação a si mesmo; reconhecimento e aceitação de vários aspectos do self, incluindo boas e más qualidades; e os níveis de sentimentos positivos sobre a vida passada (Ryan \& Decy, 2001; Keys, Shmotkin \& Ryff, 2002; Diener et al, 2009; Walendy de Freitas, 2014).

De acordo com Diener, Suh e Oishi (1997) Bem Estar Subjetivo é um campo de estudo da psicologia que tem por finalidade compreender os processos subjetivos de avaliação que as pessoas fazem sobre suas vidas em termos cognitivos e em termos de experiências afetivas, mais especificamente no que diz respeito aos níveis emocionais e aos sentimentos de satisfação com a vida. Nesse sentido, Bem Estar Subjetivo é um conceito definido como sendo a avaliação a respeito das próprias respostas emocionais (positivas e negativas) que as pessoas dão, no dia a dia, e acerca de julgamentos de satisfação quanto aos domínios específicos da vida e julgamentos de satisfação global com a vida. Estas avaliações incluem 
julgamentos afetivos, como alegria e tristeza; a satisfação com os domínios específicos da vida, tais como a satisfação com o trabalho, relacionamentos, saúde, recreação, propósito e outros domínios importantes; e satisfação global com a vida atual, com o passado, com o futuro, e com a própria capacidade de mudar de vida e outros pontos relevantes (Diener \& Ryan, 2009; Pavot \& Diener, 2008; Diener, Suh, Lucas \& Smith, 1999; Chmiel; Brunner; Martin \& Schalke, 2011; Walendy de Freitas, 2009; 2014).

Estudo de Keys; Ryff \& Shmotkin, (2002) mostrou que o Bem Estar Psicológico e o Subjetivo são dois conceitos distintos que são significativamente e positivamente relacionados.

O conceito de Bem Estar Espiritual é definido pelos aspectos transcendentes e significativos da religiosidade e da espiritualidade. De acordo com Ellison $(1991$; 1998) refere-se à experiência que as pessoas têm que pode ser denominada de espiritual e nesse sentido é um conceito que envolve duas dimensões: a religiosa e a existencial do bem estar. Bem Estar Religioso enfoca os significados e sentimentos relacionados à Divindade; e a dimensão existencial inclui significados e sentimentos relativos à forma como alguém aprecia e dá sentido à vida. A dimensão religiosa do conceito é expresso em termos de níveis de crença sobre o amor os cuidados de Deus para com o indivíduo, níveis de satisfação na experiência da prece, bem como em níveis de sentimento que há uma relação significativa com Deus. A dimensão Existencial do conceito é expressa em termos de níveis de apreciação da vida e crença de que ela é uma experiência positiva, com um propósito e sentido existencial definidos e níveis relativos ao sentimento de estar bem e tranquilo quanto ao futuro.

Estudo de Ellison (1991) mostrou que os indivíduos, com forte fé religiosa que lhes confere sentido à vida, relatam níveis mais elevados de satisfação com a vida, maior felicidade pessoal, e menos consequências psicossociais negativas de eventos de vida traumáticos.

Marques, L. F.; Sarriera, J. C.; Dell’’Aglio, D. D. (2009) adaptaram e validaram a escala de Bem Estar Espiritual para a realidade Brasileira. Com base nesse escala, Marques (2003) investigou a relação entre o Bem Estar Espiritual e a saúde geral. Os resultados mostraram que há uma correlação positiva e significativa entre a saúde e o Bem Estar Espiritual. A aplicação deste estudo aponta para a necessidade de inclusão da espiritualidade na concepção de saúde combinado com domínios biológicos, psicológicos e sociais, bem como confirma que a espiritualidade pode dar um contributo importante para a promoção da saúde e prevenção de doenças.

\section{CONCEITO DE SUPORTE SOCIAL}

Segundo a definição de Cobb (1976) o Suporte Social é definido como sendo aqueles recursos provenientes de outras pessoas, que levam o indivíduo a acreditar que é alvo de cuidados, que é amado, estimado, bem como, a sentir que é um membro pertencente a uma rede de apoio mútuo. Segundo o 
modelo de estudo desenvolvido por Cohen e Mckay (1984), esses recursos de apoio, cuja função é a proteção dos efeitos do estresse em situações críticas, são de três tipos: recursos de apoio tangível ou material; recursos informacionais ou de avaliação cognitiva; e recursos de avaliação emocional. O suporte tangível ou material é um protetor de estresse que consiste de ajuda financeira, cuidados e outras formas de assistência material. Destaca-se que esse tipo de ajuda somente é efetivo quando não cause constrangimento ou perda de liberdade que acentue o estresse. $\mathrm{O}$ suporte de avaliação cognitiva é um mecanismo que enfatiza a avaliação dos aspectos externos da situação estressora. Consiste de informações que podem ajudar uma pessoa a avaliar o evento estressor de forma menos ameaçadora e mais benigna. Quando um evento é avaliado como ameaçador e uma resposta de enfrentamento apropriada não é disponível ocorre uma reação de estresse. O suporte emocional é um mecanismo que enfatiza a avaliação que as pessoas fazem de seus sentimentos a respeito de si próprios e consiste de informações relativas à melhoria da autoestima e do sentimento de pertencer a um grupo.

Estudos sobre intervenções de suporte social mostram que os recursos de apoio são positivamente e significativamente associados a melhores níveis de saúde e de bem estar (Rodriguez \& Cohen, 1998) e o estudo de Gallagher \& Vella-Brodrick (2008) mostrou que o suporte social influencia significantemente e positivamente o bem estar.

Rabelo e Néri (2006) afirmam, com base em seu levantamento de estudos brasileiros e estrangeiros, que as pessoas afetadas por acidente vascular cerebral - AVC - apresentam menor bem estar subjetivo com relação à população em geral, contudo ressaltam os autores que os dados apontam para o fato de que a boa capacidade cognitiva, o suporte social efetivo, a continuidade de uma ocupação produtiva, a manutenção da competência em atividades da vida diária e humor positivo são fatores que melhoram o bem estar subjetivo dessa população.

\subsection{PARADIGMA LIFESPAN E TEORIA DA SELETIVIDADE SOCIOEMOCIONAL}

Teorias baseadas no paradigma de desenvolvimento LifeSpan consideram que fatores associados ao decorrer do tempo, tais como a idade, são indicadores para estudos relativos à constância e mudança no comportamento ao longo da vida. Baseada na visão LifeSpan, a Teoria da Seletividade Socioemocional sustenta que, com o avançar da idade as pessoas tentam selecionar alvos, situações e relações sociais que lhes proporcionem experiências emocionais significativas, decorrendo disso a possibilidade de um funcionamento social e emocional semelhante ou melhor do que os dos adultos mais jovens. Pesquisas têm mostrado que a frequência de emoções negativas tende a diminuir proporcionalmente ao avanço da idade porque idosos tentam manter sua mente mais atentos a memórias e informações positivas, bem como tendem a não prestar atenção a informações negativas, contudo essa tendência a ser mais positivo 
na idade avançada depende também de outros fatores e experiências que ocorreram na infância e fase adulta. (Charles \& Carstensen, 2010 ).

As repostas emocionais positivas e negativas são dois componentes do conceito de Bem Estar Subjetivo. Partindo-se do princípio da Logoterapia de que o bem estar é uma consequência do sentido e, levando-se em conta os resultados que mostram que os índices de emoções negativas tendem a diminuir com o avanço da idade, porque os idosos tendem a focar sua mente em memórias e informações mais positivas, é possível supor que isso se deva ao fato de que, com o passar do tempo, as pessoas mudem sua visão sobre a vida, decorrendo disso a hipótese de que tanto o bem estar quanto os significados existenciais devam apresentar níveis diferenciados em função da idade.

\subsection{PRESSUPOSTOS DE ANÁLISE}

Os estudos e reflexões aqui mencionados, levaram à suposição de que existiriam relações de influência entre o Sentido atribuído à vida, o Bem Estar e o Suporte Social ao longo do ciclo de vida. A fim de verificar essas relações de influência utilizou-se como representante para o Sentido atribuído à vida a Dimensão Existencial do Bem Estar Espiritual e a Idade para representar o indicador da constância e mudança na subjetividade ao longo do ciclo da vida. Além disso, optou-se por distinguir, no modelo, as questões referentes ao Sentido e apreciação da vida das referentes aos sentimentos de estar bem e tranquilo quanto ao futuro. A Tabela 1 apresenta o esquema da hipótese de antecedência e consequência entre as variáveis assumidas neste estudo e a Tabela 2 apresenta os fatores que compõem as variáveis de estudo.

Tabela 1 Hipótese de Antecedência e Consequência Entre as Variáveis de Estudo

\begin{tabular}{lll}
\hline 1 & 2 & 3 \\
\hline
\end{tabular}

DIMENSÃO EXISTENCIAL DO BEM ESTAR ESPIRITUAL

Sentido e Apreciação da Vida

Sentimentos quanto ao futuro

\section{BEM ESTAR}

SUPORTE SOCIAL

\begin{tabular}{cc}
\hline $3 \mathrm{a}$ & $3 \mathrm{~b}$ \\
\hline Psicológico & Subjetivo \\
\hline
\end{tabular}

IDADE

Indicador da constância e mudança ao longo do ciclo da vida 
Tabela 2 Fatores que compõem as variáveis de estudo

\begin{tabular}{|c|c|c|c|}
\hline $\begin{array}{c}1 \\
\text { DIMENSÃO EXISTENCIAL DO } \\
\text { BEM ESTAR ESPIRITUAL }\end{array}$ & $\stackrel{2}{\text { SUPORTE SOCIAL }}$ & BEM & STAR \\
\hline $\begin{array}{l}\text { Sentido e Apreciação de Vida: } \\
\text { A vida tem muito sentido. } \\
\text { Sei quem sou, de onde vim/vou. } \\
\text { Há um verdadeiro propósito p/minha } \\
\text { vida. } \\
\text { A vida é cheia de felicidade. } \\
\text { Sinto-me } \\
\text { realizado/satisfeito. } \\
\text { A vida é uma experiência positiva. } \\
\text { Aprecio muito a vida } \\
\text { Sentimentos Quanto ao Futuro: } \\
\text { Sinto-me bem quanto ao meu futuro. } \\
\text { Sinto bem estar c/o rumo de minha } \\
\text { vida } \\
\text { Sinto-me tranquilo com meu futuro }\end{array}$ & $\begin{array}{l}\text { Prático } \\
\text { Ajuda concreta e } \\
\text { Informações } \\
\text { cognitivas que } \\
\text { ajudam a pessoa } \\
\text { sentir que o estressor } \\
\text { é menos ameaçador } \\
\text { Emocional } \\
\text { Informações } \\
\text { cognitivas que } \\
\text { favorecem a pessoa a } \\
\text { se sentir amada e } \\
\text { pertencente a uma } \\
\text { rede social de ajuda } \\
\text { mútua }\end{array}$ & $\begin{array}{l}\text { 3a } \\
\text { Psicológico } \\
\text { Propósito } \\
\text { Autonomia } \\
\text { Autoaceitação } \\
\text { Relações positivas } \\
\text { c/outros } \\
\text { Crescimento pessoal } \\
\text { Domínio do ambiente }\end{array}$ & $\begin{array}{l}\text { 3b } \\
\text { Subjetivo } \\
\text { Afetos positivos } \\
\text { Afetos negativos } \\
\text { Satisfação global } \\
\text { c/vida } \\
\text { Satisfação c/ domínios } \\
\text { específicos da vida }\end{array}$ \\
\hline
\end{tabular}

\section{MÉTODO}

\subsection{PARTICIPANTES}

Participaram da pesquisa 205 trabalhadores de empresas privadas e públicas, na ativa e aposentados, bem como trabalhadores autônomos com a idade de 16 a 88 anos. A idade média foi de 40,7 anos, dos quais $65,4 \%$ do sexo feminino e $34,6 \%$ masculino; $41 \%$ casados, $40,0 \%$ solteiros, $12,7 \%$ divorciados, 7\% viúvos e 4\% outros tipos de vínculo. Quanto às religiões professadas: Espiritismo:23,0\%; Catolicismo: 20.6\%; Espiritualista ou Ecumênico ou professando duas ou mais religiões: 13.9\%; sem religião mas acreditam em Deus: 11.2\%; Evangélicos ou Protestantes: 10.8\%; Religiões Afro e outras: $2.0 \%$; sem informação: $18.5 \%$.

\subsection{MEDIDAS}

Os participantes foram solicitados a responder cinco questionários de autopreenchimento desenvolvidos e validados para o Brasil descritos a seguir:

\subsection{DIMENSÃO PARA MEDIR O BEM ESTAR EXISTENCIAL}

Escala de Bem Estar Espiritual é composta por duas dimensões a religiosa e a existencial. Neste estudo utilizou-se somente a dimensão existencial por apresentar questões que representam o sentido atribuído à vida. Esta escala que foi desenvolvida e validada por Marques; Sarriera \& Dell'Aglio (2009) mede os níveis de concordância ou discordância sobre 20 declarações (discordo totalmente = 1; discordo mais do que concordo $=2$; discordo levemente $=3$, concordo parcialmente $=4$, concordo mais do que 
discordo $=5$; concordo plenamente $=6)$. A dimensão existencial tem 10 itens $(\mathrm{a}=0,92)$, tais como: sinto que a vida é uma experiência positiva; estou preocupado com o meu futuro; acredito que há algum propósito real para a minha vida, sinto-me bem a cerca do meu futuro.

\subsection{DIMENSÃO PARA MEDIR O BEM ESTAR PSICOLÓGICO}

Escala de Bem Estar Psicológico desenvolvida e validada por Queroz \& Neri, (2006) $(a=0,88)$ é composta por 13 itens. Nesta escala os participantes classificam frases que melhor representam como eles veem a si mesmos (muito pouco $=1$; pouco $=2$; neutro $=3$; muito $=4$; extremamente $=5$ ), tais como: os outros me descrevem como uma pessoa generosa e disposta a compartilhar experiências; sinto que eu sou capaz de decidir por mim mesmo o que é certo; posso atender as múltiplas responsabilidades da minha vida diária; gosto de muitos aspectos da minha personalidade.

\subsection{DIMENSÕES PARA MEDIR BEM ESTAR SUBJETIVO:}

(1) Afetos Positivos e Negativos: escala desenvolvida e validada por Siqueira, Martins \& Moura (1999) com14 itens que medem a frequência de emoções na vida diária (nada=1; raramente=2; neutro=3; muitas vezes $=4$; extremamente $=5)$; Afetos Positivos $(a=0,87)$ tais como satisfação, felicidade, alegria; Afetos Negativos $(a=0,88)$ tais como irritação, depressão , desânimo.

(2) Escala de Satisfação com Vida desenvolvida e validada por Siqueira, Gomide Jr \& Freire (1996) é composta por 15 itens $(\mathrm{a}=0.84)$. Esta escala mede a frequência com que o participante se sentiu satisfeito na vida diária (muito insatisfeito $=1$; insatisfeito $=2$; nem insatisfeito nem satisfeito $=3$; satisfeito $=4$; muito satisfeito $=5$ ) através das questões relativas à satisfação com domínios específicos da vida relativos à disposição física, relacionamentos, trabalho, lazer, condições financeiras e questões relacionadas à satisfação global com a vida relacionados à capacidade de fazer as coisas que quer no presente; expectativas quanto ao futuro; e satisfação quanto às realizações no passado.

\subsection{DIMENSÕES PARA MEDIR PERCEPÇÃO DE SUPORTE SOCIAL}

Escala de Percepção de Suporte Social desenvolvida e validada por Siqueira (2008), com duas dimensões que medem a frequência com que os participantes percebem o apoio exterior na vida diária (nunca $=1$; às vezes $=2$; muitas vezes $=3$; sempre $=4)$. A dimensão de Suporte Emocional $(\mathrm{a}=0.92)$ tem 10 itens, tais como: quando preciso eu tenho alguém que: comemora comigo minhas alegrias e realizações; compreende meus problemas; me consola quando estou triste. A dimensão de Suporte Prático $(\mathrm{a}=0.91)$ tem 19 itens (instrumentais e informacionais), tais como: quando preciso eu tenho alguém que: 
me ajuda a resolver um problema prático; me dá algo que eu preciso; esclarece as minhas dúvidas; dá sugestões sobre o meu futuro.

\subsection{PROCEDIMENTOS}

Os trabalhadores foram solicitados no próprio local de trabalho e ou pela internet a responderem questões sobre dados demográficos e os questionários validados descritos anteriormente.

Para verificar os padrões de influência entre as variáveis estudadas, utilizou-se como modelo de análise o Partial Least Square-Path Modeling (PLS-PM).

\section{RESULTADOS E DISCUSSÃO}

A partir do modelo de análise referido, PLS-PM, que utiliza a variância como um indicador de influência de uma variável sobre outra, obteve-se as relações significativas apresentadas na figura 1 em termos de porcentagem de influência.

O modelo aplicado revelou que a dimensão Existencial do Bem Estar Espiritual e o Suporte Social são capazes de explicar 37,7\% ( $\mathrm{p}<0,01)$ do Bem Estar Psicológico e 50,8\% (p<0,01) do Bem Estar Subjetivo. O Suporte Social é capaz de explicar 2,5\% (p<0,05) e 1,3\% (p<0,05) do Bem Estar Psicológico e Subjetivo, respectivamente. Além disso, o Bem Estar Psicológico contribui com mais 10,1\% ( $\mathrm{p}<0,01)$ sobre o Bem Estar Subjetivo, revelando que o modelo foi capaz de explicar esta última variável em 60,9\% (p<0,01). O Suporte Social é explicado pelo Sentido e Apreciação da Vida em 12\% ( $<<0,01$ ). A Idade foi capaz de explicar somente a dimensão Existencial do Bem Estar Espiritual. Nesse sentido, o modelo mostrou que a idade exerce influência significativa somente sobre os fatores da dimensão existencial do Bem Estar : 6,9\% (p<0,01) sobre o Sentido e Apreciação da Vida e 7,8\% $(\mathrm{p}<0,01)$ sobre Sentir-se Bem Quanto ao Futuro.

Esses resultados mostram que à medida que as pessoas amadurecem há uma leve tendência a aumentarem os sentimentos de que a vida tem significado positivo, tem um verdadeiro propósito, bem como sentirem maior tranquilidade quanto ao futuro. O Sentido e Apreciação da Vida predominantemente influencia o Bem Estar Psicológico (29,9\%; p<0,01) e bem levemente o Bem Estar Subjetivo (4,2\%; $\mathrm{p}<0,01)$. Isto significa que apreciar e dar sentido à vida aumenta em cerca de um terço os sentimentos e atitudes relativas à autoaceitação, relações positivas com outros, o crescimento pessoal, o domínio do meio ambiente e o propósito, mas aumenta muito pouco a satisfação com a vida e as emoções positivas, bem como diminui muito pouco as emoções negativas. Contudo os maiores níveis de sentimentos e atitudes de autoaceitação, de relações positivas com outros, de crescimento pessoal, de domínio do meio ambiente e de propósito aumentam significativamente $(10,0 \% ; \mathrm{p}<0,01)$ a satisfação com a vida e as 
emoções positivas, bem como diminuem as emoções negativas. Sentir-se bem e tranquilo quanto ao futuro, predominantemente, influencia o Bem Estar Subjetivo $(45,3 \%$; $<<0,01)$ e pouco influencia o Bem Estar Psicológico (5,2\%; p<0,01). Isso significa que os fatores hedônicos emocionais positivos e de satisfação com a vida sofrem um aumento considerável e as emoções negativas diminuem quando as pessoas podem sentir tranquilidade quanto ao futuro e sentirem-se bem quanto ao rumo que suas vidas estão tomando. Contudo os fatores eudaimonicos relativos à percepção que as pessoas têm do próprio envolvimento com desafios existenciais da vida e de seu grau de funcionamento psicológico tais como atitudes de autoaceitação, de relações positivas com outros, crescimento pessoal, domínio do meio ambiente e propósito crescem muito pouco com os sentimentos positivos quanto ao futuro.

Finalmente, pode-se observar que o suporte social, em termos quantitativos, produz poucos efeitos diretos sobre o bem estar 2,6\% e 1,3\% (p<0,05), respectivamente sobre o Psicológico e sobre o Subjetivo. Contudo a percepção de Suporte Social é sensivelmente influenciada $(12 \%, \mathrm{p}<0,01)$ pelo sentido e apreciação da vida. Além disso, seu posicionamento no modelo revela que a percepção de disponibilidade de apoio social é um mediador importante entre o sentido e o bem estar. Isso sugere que as pessoas, que encontram sentido em suas vidas, têm mais habilidades sociais e estão mais abertas para distinguir e buscar, quando necessário, o apoio social adequado ao seu bem estar.

A capacidade de Bem Estar Psicológico explicar Bem Estar Subjetivo está de acordo com o estudo de Keys; Ryff \& Shmotkin, (2002) que mostrou que o Bem Estar Psicológico e o Subjetivo são dois conceitos distintos que são significativamente e positivamente relacionados.

A função do suporte social encontrada estudo está de acordo com os estudos de Rodriguez \& Cohen, (1998); Rabelo e Néri (2006) em que a mediação do suporte social é um dos fatores fundamentais para proteger a saúde e o bem estar das pessoas, bem como confirma o estudo de Gallagher $\&$ Vella-Brodrick (2008) que mostrou que o suporte social influencia significantemente e positivamente o bem estar.

Os resultados deste estudo também estão de acordo com Charles \& Carstensen (2010) quanto à tendência de que com o passar dos anos as pessoas apresentem níveis de bem estar e de funcionamento psicológico semelhantes ou melhores do que os mais jovens. Contudo o modelo mostrou que esses efeitos benéficos sobre o bem estar são produzidos pelo Sentido, porque à medida que a idade avança, as pessoas tendem a aumentar os níveis de significados essenciais atribuídos à vida e, deste modo, passam a apreciala e a sentirem-se mais tranquilas quanto ao futuro.

Isso mostra o quanto são importantes as intervenções de apoio social que afirmem a vida, durante todas as fases, como afirma Cobb (1976), mas mostra também o quanto é importante que essas 
intervenções deem ênfase ao Sentido, a fim de que, com o avanço da idade, as pessoas possam desfrutar de um funcionamento subjetivo mais favorável, apesar das perdas que possam ocorrer na idade avançada.

Finalmente, o modelo confirmou Frankl (2013) em que a felicidade, aqui definida em termos de bem estar, é um produto do Sentido, mais especificamente, o sentido existencial atribuído a vida.

Figura 1 Relações de Influência entre Sentido atribuído à vida, Suporte Social e Bem Estar ao Longo do Ciclo de Vida Adulta. Partial Least Square-Path Modeling (PLS-PM)

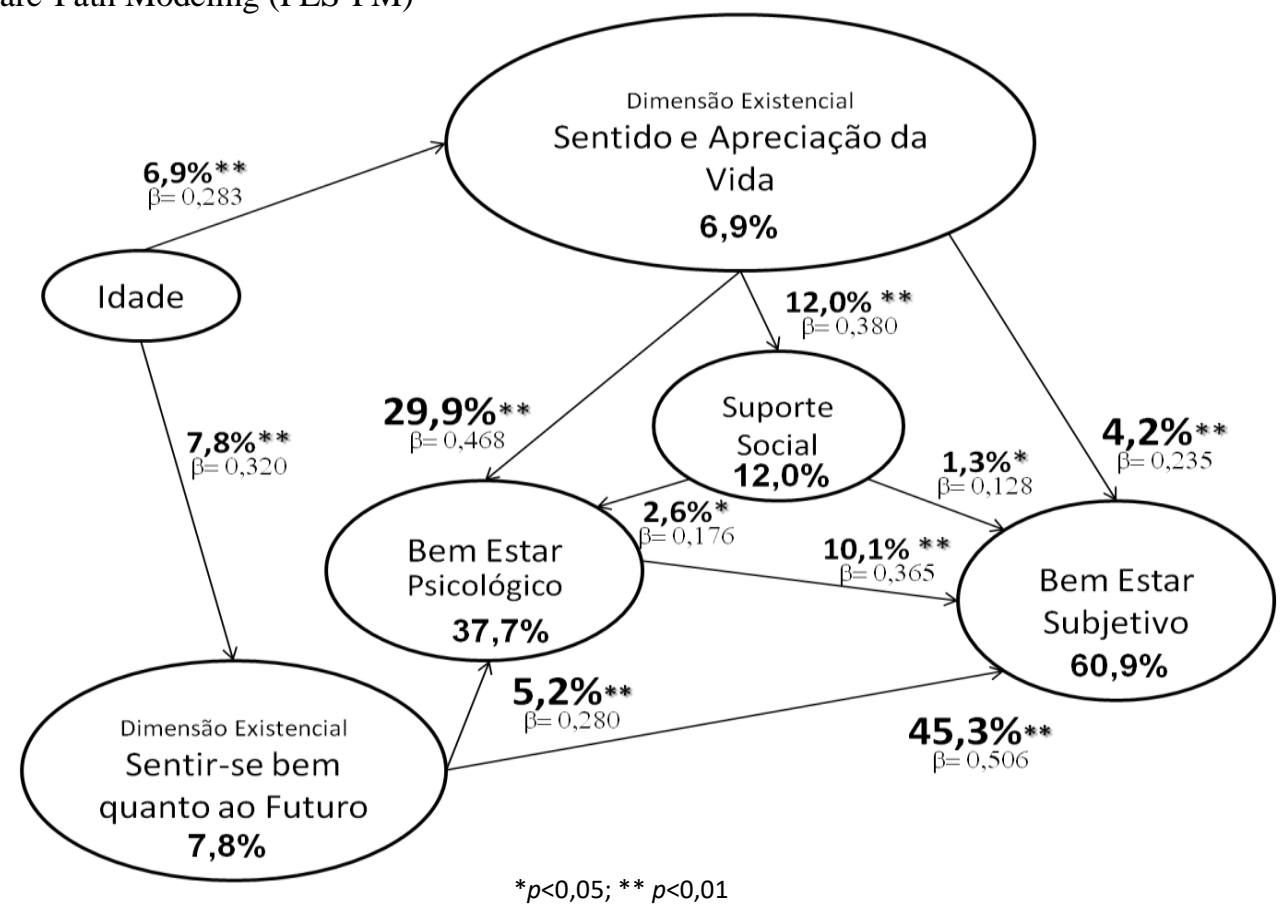

\section{CONSIDERAÇÕES FINAIS}

As análises deste estudo, baseadas em pesquisas com trabalhadores, apontam para a relevante influência do sentido da vida sobre o bem estar, confirmando o modelo proposto por Frankl (2013) de que a felicidade é uma consequência do Sentido.

Este estudo mostra, que à medida que os trabalhadores amadurecem e envelhecem, há uma tendência a aumentar a presença positiva do sentido existencial em sua subjetividade, tanto no que diz respeito a apreciarem e sentirem que a vida é repleta de sentido, quanto a se sentirem bem e tranquilos quanto ao futuro. Essas constatações apontam para a importância da presença de pessoas mais maduras e de idosos, nas empresas, de modo a contribuir, não somente com a experiência técnica, mas também para o desenvolvimento psicológico, para o equilíbrio emocional e consequentemente para o encontro do Sentido que favoreça o enfrentamento mais positivo de problemas no cotidiano da organização. Além disso, mostra que as causas do bom funcionamento psicológico na idade mais avançada, é determinado pelo apoio social não somente na velhice, mas durante todas as fases da vida. Contudo, para ser eficaz é 
preciso que o apoio social tenha por objetivo principal o despertamento nas pessoas do real Sentido de suas vidas.

Este estudo mostra também que o sentido atribuído à vida é responsável por afetar sensivelmente e positivamente o desenvolvimento psicológico humano e a maneira como as pessoas se defrontam com os desafios existenciais da vida; porque apreciar a vida e acreditar que ela tem um verdadeiro e positivo propósito afeta diretamente o grau de funcionamento psicológico e, por conseguinte, influencia diretamente a percepção e atitudes que elas têm quanto ao próprio envolvimento com desafios existenciais da vida.

Revela também o quanto é importante às pessoas acreditarem que há um futuro promissor que as aguarda, não somente para obterem forças ante os desafios presentes em suas vidas, mas sobretudo, para aumentar a satisfação e reações emocionais positivas diante desses desafios. Essa constatação também sugere que o Sentido seja responsável por reduzir fortemente os níveis de ansiedade e outros sintomas negativos relativos ao futuro.

Além dessas constatações, este estudo confirma que o apoio social é um mediador que facilita às pessoas manterem seu equilíbrio subjetivo e, sobretudo, mostra que o Sentido existencial positivo é responsável por tornar as pessoas mais abertas e mais aptas a perceberem, bem como a buscarem os recursos de apoio que estão disponíveis em sua rede social, quando isso for necessário.

Finalmente, este estudo contribui para mostrar que os serviços de suporte social, no contexto clínico ou no contexto organizacional, terão maior êxito se fundamentarem suas intervenções em meios que facilitem para indivíduos e grupos a emergência do Sentido essencial da vida.

\section{REFEREÊNCIAS}

Charles, S.T. \& Carstensen, L.L. (2010). Social and Emotional Aging. Annual Review of Psychology, 61, 383-409.

Chmiel, M., Brunner;M. Martin, R. \& Schalke, D. (2011). Revisiting the structure of subjective WellBeing in Middle-Aged Adults. Social Indicators Research, 106, 109-116.

Cobb (1976). Social support as a moderator of life stress. American Psychosomatic Society, 38, 300-314.

Cohen, S.; Mackay, G. (1984). Social Support, Stress and the Buffering Hypothesis: A Theoretical Analysis. In Baum, A.; Taylor, S. E.; Singer, J.E. (eds). Handbook of Psychology and Health. NJ. Hillsdale. 1984.

Diener, E., \& Ryan, K. (2009). Subjective well-being: a general overview. South African Journal of Psychology, 39, 391-406. 
Diener, E., Wirtz, D., Biswas-Diener, R., Tov, W., Kim-Prieto, C., Choi, D. \& Oishi, S. (2009). New Measures of Well-Bieng. In Diener, E. (Ed), Assessing Well-Being. p.247-266.

Diener, E.; Suh, E. M.; Lucas, E. R.; Smith, H. (1999) Subjective Well-Being: Three Decades of Progress. American Psychological Association. Psychological Bulletin, v.125, p.276-302.

Diener, E.; Suh, E.; Oishi, S. (1997). Recentes Findings on Subjective Well-Being. Indian Journal of Clinical Psychology

Ellison, C. G. (1991) Religious Involvement and Subjective Well- Being. Journal of Health and Social Behavior, v. 32,n.1, p.80-99.

Ellison, C. G.; Levin, J. S. (1998) The Religion - Health Connection: Evidence, Theory and Future Directions. Health Educations \& behavior, v. 25(6), p.700-720.

Frankl, V. E. (2003) Psicoterapia e Sentido da Vida: Fundamentos da Logoterapia e Análise Existencial. Quadrante. São Paulo. 4a ed. p.55-137.

Frankl, V. E. (2003a). Em busca de sentido. Sinodal-Vozes. Petrópolis. 18 a ed. p.91-112.

Frankl, V. E. (2013). A vontade de sentido: fundamentos e aplicações da logoterapia. São Paulo. $2^{\mathrm{a}}$ ed. p. 48-50.

Gallagher, E. N. \& Vella-Brodrick, D. A. (2008). Social support and emotional intelligence as predictors of subjective well-being. ScienceDirect. Elsevier. Personality and Individual Differences, 44, 1551-156.

Keys, Shmotkin \& Ryff, 2002; Keyes, C. L. M., Shmotkin, D. \& Ryff, C. D. (2002). Optimizing WellBeing: The Empirical Encounter of Two Traditions. American Psychological Association. Journal of Personality and Social Psychology, 82 (6), 1007-1022.

Marques (2003). Marques, L. F. (2003). A saúde e o bem-estar espiritual em adultos portoalegrenses. Psicologia Ciência e Profissão, 23 (2), 56-65.

Marques, L. F.; Sarriera, J. C.; Dell’Aglio, D. D. (2009). Marques, L. F.; Sarriera, J. C.; Dell’Aglio, D. D. (2009). Marques, L. F., Sarriera, J. C., \& Dell'Aglio, D. D. (2008). Adaptação e validação da Escala de Bem-estar Espiritual (EBE). Avaliação Psicológica, 8, 179-186.

Neri, A. L. (2001) Envelhecimento e Qualidade de Vida da Mulher. Anais do $2^{\circ}$ Congresso de Geriatria e Gerontologia. http://scholar.google.com.br/scholar. Acesso em agosto 2009.

Oliveira, E. K. de S. \& Silva, J. P. da (2013). Sentido de vida e envelhecimento: relação entre os pilares da logoterapia e bem estar psicológico. Logos \& Existência. Revista Da Associação Brasileira De Logoterapia E Análise Existencial 2 (2), 135-146.

Pavot, W. Diener, E. (1993). Review of Psychological Satisfaction With Life Scale. American Psychological Association. Psychological Assesment,.v.5,n.2, p.164-172.

Queroz, N.C.; Neri, A. L. (2005) Bem- estar Psicológico e Inteligência Emocional entre Homens e Mulheres na Meia-idade e na Velhice. Psicologia Reflexão e Crítica 18(2), p. 292-299. 
Rabelo, D. F.; Neri, A. L. (2006). Bem-estar Subjetivo e Senso de Ajustamento Psicológico em Idosos que Sofreram Acidente Vascular Cerebral: Uma Revisão. Estudos de Psicologia, 11(2), p. 169-177.

Rodrigues, R. (1991). Fundamentos da Logoterapia na clínica psiquiátrica e psicoterapêutica. Petrópolis. Vozes. v.1. p.56-69.

Rodriguez, M., \& Cohen, S. (1998). Social Support. In Friedman, H. (ed.) Encyclopedia of Mental Health. New York: Academic Press. p. 535-544.

Ryan, R. M. \& Deci, E. L. (2001). On happiness and human potentials: a review of research on hedonic and eudaimonic well-being. Annu. Rev. Psychol. 52,141-166.

Simões, A. S.; Kluppel, B. L. P. \& Sousa, S. (2012). Bem estar espiritual e síndrome de bornout em psicólogos de hospitais públicos em João Pessoa/PB. Logos \& Existência. Revista Da Associação Brasileira De Logoterapia E Análise Existencial 1 (2), 192- 202.

Siqueira, M.M.M. (2008). Construção e Validação da Escala de Percepção de Suporte Social. Psicologia em Estudo.

Siqueira, M.M.M., Martins, M.C.F., Moura, O . I. (1999). Construção e Validação Fatorial da EAPN: Escala de Ânimo Positivo e Negativo. Revista da SPTM. 2. p. 34-40.

Walendy de Freitas (2014). The Influence Relations Among Three Traditions of Well-Being and Social Support, and the Associations With Age and Health. In Solano, A. C. (ed). Positive Psychology in Latin America. Dordrecht Heidelberg New York London. Springer. p. 255-273.

Walendy de Freitas, L. H. (2009). Otimismo, Suporte Social e Valores do Trabalho como Antecedentes do Bem Estar Subjetivo de Trabalhadores. Dissertação de Mestrado, Universidade Metodista de São Paulo. 